\title{
Anti-angiogenic effect of siphonaxanthin from green alga, Codium fragile.
}

\section{$\operatorname{AUTHOR}(S):$}

Ganesan, Ponesakki; Matsubara, Kiminori; Ohkubo, Takeshi; Tanaka, Yukihisa; Noda, Kenji; Sugawara, Tatsuya; Hirata, Takashi

\section{CITATION:}

Ganesan, Ponesakki ... [et al]. Anti-angiogenic effect of siphonaxanthin from green alga, Codium fragile.. Phytomedicine: international journal of phytotherapy and phytopharmacology 2010, 17(14): 1140-1144

\section{ISSUE DATE:}

2010-12-01

URL:

http://hdl.handle.net/2433/131855

\section{RIGHT:}

(c) 2010 Elsevier GmbH; This is not the published version. Please cite only the published version.; この論文は出版社版でありません。引用の 際には出版社版をご確認ご利用ください。 


\section{Anti-angiogenic effect of siphonaxanthin from green alga, Codium}

$$
\text { fragile }
$$

Ponesakki Ganesan $^{\mathrm{a}}$, Kiminori Matsubara ${ }^{\mathrm{b}}$, Takeshi Ohkubo ${ }^{\mathrm{c}}$, Yukihisa Tanaka ${ }^{\mathrm{c}}$, Kenji

Noda $^{a}$, Tatsuya Sugawara ${ }^{\mathrm{a},}{ }^{*}$, Takashi Hirata ${ }^{\mathrm{a}}$

${ }^{a}$ Division of Applied Biosciences, Graduate School of Agriculture,

Kyoto University, Kyoto 606-8502, Japan

${ }^{b}$ Department of Human Life Sciences Education, Graduate School of Education,

Hiroshima University, Higashi Hiroshima 739-8524, Japan

${ }^{c}$ NOF Corporation, Kawasaki 210-0865, Japan

* Corresponding author:

Tel: $+81-75-753-6212$

Fax: +81-75-753-6212

E-mail address: sugawara @kais.kyoto-u.ac.jp

Running title: Anti-angiogenic effect of siphonaxanthin 


\section{Abstract}

Since anti-angiogenic therapy has becoming a promising approach in the prevention of cancer and related diseases, the present study was aimed to examine the anti-angiogenic effect of siphonaxanthin from green alga (Codium fragile) in cell culture model systems and ex vivo approaches using human umbilical vein endothelial cells (HUVEC) and rat aortic ring, respectively. Siphonaxanthin significantly suppressed HUVEC proliferation $(\mathrm{p}<0.05)$ at the concentration of $2.5 \mu \mathrm{M}(50 \%$ as compared with control $)$ and above, while the effect on chemotaxis was not significant. Siphonaxanthin exhibited strong inhibitory effect on HUVEC tube formation. It suppressed the formation of tube length by $44 \%$ at the concentration of $10 \mu \mathrm{M}$, while no tube formation was observed at $25 \mu \mathrm{M}$, suggesting that it could be due to the suppression of angiogenic mediators. The ex vivo angiogenesis assay exhibited reduced microvessel outgrowth in a dose dependent manner and the reduction was significant at more than $2.5 \mu \mathrm{M}$. Our results imply a new insight on the novel function of siphonaxanthin in preventing angiogenesis related diseases.

Keywords: Angiogenesis; Siphonaxanthin; Endothelial cells; Aortic ring 


\section{Introduction}

Angiogenesis is the growth and remodeling process of the primitive network of blood vessel into a complex network. In this process, endothelial cells secrete proteases, migrate through the extracellular matrix, proliferate and differentiate (Folkman and Shing, 1992). In normal adult, most vasculature is quiescent, with only $0.01 \%$ of endothelial cells undergoing division (Carmeliet and Jain, 2000). However, angiogenesis is essential for the female reproductive cycle, and remodeling and regeneration of tissues (Folkman, 1995). Pathological angiogenesis is implicated in the pathogenesis of many diseases including cancer, atherosclerosis, rheumatoid arthritis and diabetic retinopathy (Virmani et al., 2005; Miyazawa et al., 2008). The newly formed blood vessels can promote cancer growth by supplying nutrients and oxygen and by removing waste products. Metastasis also depends on angiogenesis, as tumor cells are shed from a primary tumor and grow at their target organ (Folkman, 1976). Angiogenesis is also switched on under other pathological conditions such as ocular and inflammatory disorders (Carmeliet, 2005). Hence, preventing angiogenesis under pathological conditions is a promising approach in the prevention of cancer and other proangiogenic diseases.

Targeting angiogenesis for human cancer therapy, FDA approved bevacizumab, a humanized anti-VEGF monoclonal antibody, for the treatment of metastatic colorectal 
cancer in combination with 5-fluorouracil (FU)-based chemotherapy regimens (Ferrara and Kerbel, 2005). Recently, statin derivatives such as endostatin and caplostatin are widely used for anti-angiogenic therapy (Abdollahi et al., 2004; Satchi-Fainaro et al., 2005). Moreover, several anti-angiogenic drugs (ZD6474, AZD2171 and vatalanib/PTK787) are currently being under clinical trials (Hanrahan and Heymach, 2007; Scot et al., 2007). But, most of these angiogenic inhibitors are in important concerns with side effects in animals and humans (Folkman, 2007). Considering these perspectives, search for natural compounds have received considerable attention to overcome the adverse effect of synthetic compounds on human health.

Marine macroalgae are potential renewable resource in the marine environment, used as culinary items in the Orient and have been reported to afford several beneficial effects. They are the excellent source of bioactive compounds such as carotenoids, dietary fiber, amino acids, essential fatty acids, vitamins and minerals (Mabeau and Fleurence, 1993; Fleurence, 1999). However, effect of algal components on angiogenesis remained unknown or scanty. Considering this background, our previous studies on natural bioactive molecules from marine algae have reported and demonstrated that fucoidans, a polysaccharide from marine brown algae, and fucoxanthin and its deacetylated product, fucoxanthinol exert anti-angiogenic properties (Matsubara et al., 2005a; Sugawara et al., 
2006). Fucoxanthin, a widely studied xanthophyll carotenoid of brown algae, and its metabolites have been reported to possess several health beneficial effects such as anti-cancerous, anti-oxidative and anti-obesity properties (Kotake-Nara et al., 2001; Sugawara et al., 2002; Kotake-Nara et al., 2005; Miyashita and Hosokawa, 2008; Sugawara et al., 2009).

Siphonaxanthin (Fig. 1) is a specific keto-carotenoid of siphonaceous green algae, which helps in absorbing available green and blue green light in underwater condition (Akimoto et al., 2007; Chen et al., 2008) and its biofunctional aspects are yet to be studied. The present study aimed to evaluate the anti-angiogenic effect of siphonaxanthin form green alga (Codium fragile) in order to get a new vision for further research on angiogenesis using marine carotenoids. With the best of our knowledge, this is the first report on the biofunctional properties of siphonaxanthin.

\section{Materials and Methods}

\section{Materials}

Codium fragile, green alga was donated by NOF Corporation, Tokyo, Japan. Human umblical vein endothelial cells (HUVECs) were purchased from Kurabo Industries (Osaka, Japan). WST-1 reagent was obtained from Dojindo Laboratories (Kumamoto, 
Japan). Human recombinant vascular endothelial growth factor (VEGF) was from R\&D

Systems (MN). Male Wistar rats were procured from Charles River Laboratories

(Kanagawa, Japan). All other reagents, media, buffered solutions and solvents were special grades commercially available.

\section{Sample extraction and purification}

Fresh Codium fragile used in this study were freeze dried and made into powder.

Siphonaxanthin was extracted and purified from the freeze dried algal powder. Briefly, acetone extract was prepared by mixing acetone at the ratio of 1:20 (w/v) and the mixture was kept on a magnetic stirrer at $4^{\circ} \mathrm{C}$ for overnight under dark conditions. This extraction procedure was repeated twice from the same powder. Resulted extracts were pooled together and condensed by evaporating under reduced pressure using rotary flash evaporator. Acetone extract was then subjected to preparative HPLC (LC-9A, Shimadzu, Japan) on a Lichroprep RP-18 (40-63 $\mu \mathrm{m}, 11$ x 240 mm, Merck, Germany) column and eluted with a acetonitrile and water mixture at the ratio of 9:1 (v/v). Yellow colored siphonaxanthin rich fraction was further purified by reverse phase HPLC (LC-6AD, Shimadzu, Japan) on a TSKgel ODS-80Ts QA (4.6 x 250 mm, Tosoh, Japan) column. The purification was carried out using mixture of acetonitrile, methanol and water $(75: 15: 10, \mathrm{v} / \mathrm{v} / \mathrm{v})$ containing $0.1 \%(\mathrm{w} / \mathrm{v})$ ammonium acetate as a mobile phase at a 
flow rate of $1 \mathrm{ml} / \mathrm{min}$. Siphonaxanthin was identified by UV-vis spectrum using a

LC-6AD HPLC system equipped with a photodiode array detector (Shimadzu, Japan), and mass spectrum using a HPLC system connected to a mass spectrometer (LCMS-2010EV, Shimadzu, Japan) equipped with an interface of atmospheric pressure chemical ionization. Purified siphonaxanthin (98\%) was stored at $-80{ }^{\circ} \mathrm{C}$ for further experiments.

\section{Cell culture}

HUVECs were grown in a modified MCDB 131 medium (HuMedia EG2 from Kurabo Industries, Japan) containing 2\% fetal bovine serum (FBS), $10 \mathrm{ng} / \mathrm{ml}$ recombinant human epidermal growth factor (EGF), $1 \mu \mathrm{g} / \mathrm{ml}$ hydrocortisone, $50 \mu \mathrm{g} / \mathrm{ml}$ gentamycin, $50 \mathrm{ng} / \mathrm{ml}$ amphotericin $\mathrm{B}, 5 \mathrm{ng} / \mathrm{ml}$ recombinant human basic fibroblast growth factor (bFGF) and $10 \mu \mathrm{g} / \mathrm{ml}$ heparin. Cells were cultured at $37^{\circ} \mathrm{C}$ in humidified condition with $5 \% \mathrm{CO}_{2}$. Subcultures were obtained by treating the HUVEC cultures with enzyme-free Hanks`-based cell dissociation buffer (Gibco, New York, USA). HUVECs at passages three to five were used for the experiment. Proliferation assay

HUVEC suspension $\left(1.5 \times 10^{4}\right.$ cells/ml) was plated onto 96 -well plates (100 $\mu \mathrm{l} /$ well). After $24 \mathrm{~h}$, the medium was replaced with fresh HuMedia containing shiphonaxanthin using dimethyl sulfoxide (DMSO) as vehicle with the final concentration of $0.1 \%$. 
Control culture received the vehicle alone. After $72 \mathrm{~h}, 10 \mu \mathrm{l}$ of WST-1 reagent was added into each well and incubated at $37^{\circ} \mathrm{C}$ for $4 \mathrm{~h}$. Absorbance at $450 \mathrm{~nm}$ was measured using a spectrophotometer.

\section{Chemotaxis assay}

HUVEC chemotaxis assay was carried out by a modified Boyden chamber assay (Kim et al., 2003). Microporous membrane $(8 \mu \mathrm{m})$ of 24 well culture inserts (BD Biosciences, MA) were coated with $0.1 \%$ gelatin. HUVECs were detached with cell dissociation buffer (Invitrogen Corp., Carlsbad, CA), collected by centrifugation, resuspended in Medium 199 (Invitrogen) with 0.1\% bovine serum albumin (BSA), and seeded in triplicate in the chamber $\left(1.0 \times 10^{5}\right.$ cells $\left./ 400 \mu \mathrm{l}\right)$. The well was then filled with $400 \mu \mathrm{l}$ Medium 199 containing $0.1 \%$ BSA and $10 \mathrm{ng} / \mathrm{ml}$ VEGF with or without siphonaxanthin. The assembled chamber was cultured for $6 \mathrm{~h}$. Non-migrated cells on the upper surface of the membrane were removed by scrubbing with a cotton swab. Cells on the lower surface of the membrane were fixed with methanol and stained with Diff-Quik stain (Sysmex, Japan). Migrated cells were counted in five fields of each membrane under the microscope at $200 \mathrm{x}$ magnification, and the average number of a field was calculated.

\section{Tube formation assay}


HUVEC tube formation assay was performed according to the method using BD Matrigel (Becton, Dickinson and Co., Japan) (Matsubara et al., 2005a). Briefly, solid gels were prepared on a 96-well tissue culture plate according to the manufacturer guidelines. HUVECs $\left(1 \times 10^{5}\right.$ cells $\left./ \mathrm{ml}\right)$ in HuMedia EG-2 medium containing $\quad 0-50 \mu \mathrm{M}$ of siphonaxanthin was seeded $(100 \mu \mathrm{l} /$ well $)$ onto the surface on solid BD Matrigel. After 12 $\mathrm{h}$ in culture, tube formation was observed under an inverted light microscope at $40 \mathrm{x}$ magnification. Microscopic fields were photographed with a digital camera (OLYMPUS DSE330-A system). The total length of tube structures were measured using Adobe Photoshop software.

\section{Ex vivo angiogenesis assay}

Six weeks old male Wistar rats were housed two to a metal cage in a controlled temperature $\left(24 \pm 1^{\circ} \mathrm{C}\right)$ with $12 \mathrm{~h}$ light: dark cycle (lights on, 08:00 - 20:00). They had free access to diets and deionized water. The rats were maintained according to the Guide for the Care and use of Laboratory Animals established by Hiroshima University. The ex vivo angiogenesis assay was performed according to slightly modified methods as described previously (Mori et al., 1988; Kawasaki et al., 1989). Briefly, a male Wistar rat (body weight $\approx 200 \mathrm{~g}$ ) was sacrificed by bleeding from the right femoral artery under anesthesia with diethyl ether. Thoracic aorta was removed and washed with RPMI 1640 
medium to avoid contamination with blood. It was then turned inside out and cut into short segments of about $1-1.5 \mathrm{~mm}$. Collagen gel (gel matrix solution) was made with 8 volume porcine tendon collagen solution ( $3 \mathrm{mg} / \mathrm{ml}$ ) (Cellmatrix Ia, Nitta Gelatin Co., Japan), 1 volume 10 x Eagle`s MEM (Gibco, NY), and 1 volume reconstitution buffer (80 $\mathrm{mM} \mathrm{NaOH}$ and $200 \mathrm{mM}$ HEPES) and mixed gently at $4^{\circ} \mathrm{C}$. Each aortic segment was placed in the center of a well of 6 -well culture plate and covered with $0.5 \mathrm{ml}$ gel matrix solution reconstituted as described. The solution was allowed to gel at $37^{\circ} \mathrm{C}$ for $20 \mathrm{~min}$, and then overlaid with 2 ml RPMI 1640 medium containing 1\% ITS+ (Becton Dickinson Labware, MA). Sample solution or vehicle was then added. Plates were incubated for 10 days in a fully humidified system of $5 \% \mathrm{CO}_{2}$ at $37^{\circ} \mathrm{C}$. The medium was changed on day 7 of the culture. The capillary length was estimated under phase-contrast microscopy by measuring the distance from the cut end of aortic segment to the approximate mean point of capillary. Microscopic fields were photographed with a digital camera (OLYMPUS DSE330-A system). The total length of tube structures were measured using Adobe Photoshop software.

\section{Statistical analysis}

Values are presented as means $\pm \mathrm{SD}$. Data were analyzed by one-way analysis of variance with Dunnett`s test to identify significant differences $(\mathrm{p}<0.05)$. 


\section{Results}

\section{Characterization of siphonaxanthin}

HPLC profile of crude extract of Codium fragile is shown in Fig. 1a. A minor peak corresponding to siphonaxanthin was detected at $7 \mathrm{~min}$. Siphonaxanthin was identified by its characteristic UV-vis spectrum (Fig. 1b), and further characterized by the positive ions of mass spectrum at m/z $583\left[\mathrm{M}+\mathrm{H}-\mathrm{H}_{2} \mathrm{O}\right]^{+}, 565\left[\mathrm{M}+\mathrm{H}-2 \mathrm{H}_{2} \mathrm{O}\right]^{+}$and 547 $\left[\mathrm{M}+\mathrm{H}-3 \mathrm{H}_{2} \mathrm{O}\right]^{+}$(Fig. 1c).

\section{Effect of siphonaxanthin on HUVEC proliferation and migration}

Effect of siphonaxanthin on endothelial cell proliferation is shown in Fig. 2. Siphonaxanthin inhibited HUVEC proliferation by $50 \%$ at the concentration of $2.5 \mu \mathrm{M}$. The difference between control and siphonaxanthin treated HUVECs proliferation (2.5 $50 \mu \mathrm{M})$ were found to be statistically significant $(\mathrm{p}<0.05)$. Further, we examined the effect of siphonaxanthin on VEGF induced HUVEC migration (Fig. 3). VEGF was proven to be specific and critical growth factor involved in endothelial proliferation, migration and survival during blood vessel formation (Ferrara, 1999). VEGF strongly stimulated HUVEC migration, but siphonaxanthin did not show significant $(\mathrm{p}>0.05)$ effect in the presence of VEGF. These data suggest that siphonaxanthin might not be involved in the VEGF induced endothelial cell migration. 


\section{Effect on HUVEC tube formation}

HUVECs on reconstituted basement membrane migrated, attached to each other, and formed tube structures are shown in Fig. 4a. It clearly shows that the tube structures in siphonaxanthin treated basement membrane are very short and not attached each other as compared with control. Siphonaxanthin exhibited strong inhibitory effect on HUVEC tube formation at the concentration more than $10 \mu \mathrm{M}$. The tube length reduced by 5.2 $\mathrm{mm}$ (compared with control) when the concentration was $10 \mu \mathrm{M}$, while no tube formation observed at more than $25 \mu \mathrm{M}$ (Fig. 4b), which is clearly attributed in Fig. 4a.

\section{Effect on ex vivo angiogenesis}

Rat aortic ring (ex vivo) angiogenesis model was also used to examine the effect of siphonaxanthin on angiogenesis. This method is widely used to evaluate anti-angiogenic agents in a complex system in which endothelial cells, fibroblasts, pericytes and smooth muscle cells are involved (Kruger et al., 2000; Zogakis et al., 2002). Fibroblastic fusiform cells migrated from the ends of the aortic rings after 2-3 days and spread in the collagen gel. Microvessels appeared after 5-6 days and elongated (Fig. 5a). Siphonaxanthin suppressed ex vivo microvessel formation in a dose dependant manner. Significant inhibition was observed even at very low concentration $(2.5 \mu \mathrm{M})$, and the inhibition level was $100 \%$ when the concentration was at $50 \mu \mathrm{M}$ (Fig. $5 \mathrm{~b}$ ). The dose 
dependant effect of siphonaxanthin is clearly attributed in Fig. 5a.

\section{Discussion}

New blood vessels in the adult arise mainly through angiogenesis (Carmeliet 2000) implicated in the pathogenesis of many diseases, such as growth and metastasis of solid tumors, cancer, atherosclerosis, diabetic retinopathy and rheumatoid arthritis (Virmani et al., 2005). Modulation of angiogenesis is a promising strategy in the prevention and treatment of angiogenesis-mediated disorders. It has been well documented that some anti-angiogenic compounds are available in food (Mantell et al., 2000; Tsuzuki et al., 2007). We have previously demonstrated the anti-angiogenic activity of a marine brown algal polysaccharide (fucoidan) and a carotenoid (fucoxanthin) (Matsubara et al., 2005a; Sugawara et al., 2006). The present study investigated the anti-angiogenic potential of siphonaxanthin from marine alga, Codium fragile.

Recently, natural dietary compounds such as curcumin (Liu et al., 2008), nasunin (Matsubara et al., 2005b), vitamin D3 (Mantell et al., 2000), tocotrienols (Mizushina et al., 2006; Shibata et al., 2008), and fatty acids (Masso-Welch et al., 2004) have also been reported to possess anti-angiogenic effect. Siphonaxanthin showed comparable anti-angiogenic effect with previously reported natural anti-angiogenic compounds. A 
plant derived anti-angiogenic polyphenol, nasunin at the concentration of $10 \mu \mathrm{M}$ significantly suppressed ex vivo microvessel formation (Matsubara et al., 2005b). But, siphonaxanthin inhibited microvessel length by $50 \%$ at the concentration of $2.5 \mu \mathrm{M}$, indicating its potential as strong anti-angiogenic agent. Furthermore, the inhibitory effect of siphonaxanthin $(10 \mu \mathrm{M})$ on HUVEC tube formation was remarkably higher than a synthetic vitamin $\mathrm{K}$, vitamin $\mathrm{K}_{3}(25 \mu \mathrm{M})$ (Matsubara et al., 2008). However, almost similar effect on tube formation was also observed with $\alpha$-tocotrienol (Mizushina et al., 2006).

Siphonaxanthin exerted anti-angiogenic activity by significantly suppressing HUVEC tube formation and endothelial cell proliferation, but the effect on cell migration did not significant. Siphonaxanthin also inhibited microvessel formation in rat aortic ring angiogenic model. These findings are well correlated with our previous report on the anti-angiogenic effect of another keto-carotenoid, fucoxanthin (Sugawara et al., 2006). Fucoxanthin is a specific carotenoid with unique functional groups such as epoxide and allenic bond in its structure, whereas siphonaxanthin does not contain these functional groups. Thus it can be suggested that the similar effect might not be due to epoxide and allenic bond. The presence of hydroxy group on the 3 and 3' position of these carotenoids could conceivably parted in anti-angiogenesis. 
Variety of anti-angiogenic agents with diverse mechanism (several of which are not known) of action are currently in clinical trials (Ferrara and Kerbel, 2005). VEGF signaling through its receptor (VEGFR-2) is the best-characterized signaling pathway in developmental angiogenesis (Yancopoulos et al., 2000; Shibuya and Claesson-Welsh, 2006). In the present study, although siphonaxanthin had a strong inhibitory effect on tube formation in a HUVEC culture model and an ex vivo angiogenic model, it might not through signal transduction by VEGF receptor-2, exerted no significant effect on VEGF-induced HUVEC migration. Other signaling molecules such as platelet-derived growth factor (PDGF) (Lindhal et al., 1997), fibroblast growth factor (FGF) (Mori et al., 2008) and the angiopoietins (Ang) (Yancopoulos et al., 2000) might be contributed in the anti-angiogenic effect of siphonaxanthin. It has also been reported that expression of matrix metalloproteinases (MMP) may also contribute HUVEC migration and proliferation (Romanic et al., 2001). Earlier studies reported that cellular and molecular mechanisms of angiogenesis differ depending on the target tissue and microenvironmental conditions (Carmeliet, 2000; Zhu et al., 2008). These findings are likely to imply further interest in the possible molecular mechanisms of angiogenesis to reveal novel dietary-based anti-angiogenic approaches for cancer prevention.

As many vascular-disturbing agents are at present being under lengthy clinical trials, 
consumption of food-derived and natural anti-angiogenic compounds would be recommended to prevent angiogenic disorders. Considering the pathophysiology of cancer and other pro-angiogenic diseases, and their limited preventive measures, discovery of dietary-based compounds with potential anti-angiogenic properties is an important approach in improving current anti-angiogenic therapy. Seaweeds are used as food and feed ingredient in many parts of the world. They are staple diet in some countries like Japan and Korea. Fucoxanthin, a xanthophyll carotenoid, its biofunctional properties including anti-angiogenic activity are widely studied, but the functional properties of siphonaxanthin is not touched yet. The present study concludes that siphonaxanthin inhibits angiogenesis both in cell culture model systems and ex vivo, and demonstrated its potential as functional compound. It also opens up a new line of research on the role of siphonaxanthin on molecular mechanism of angiogenesis.

\section{Acknowledgement}

This work was supported by the Ministry of Education, Culture, Sports, Science and Technology (MEXT), Government of Japan. 


\section{References}

Abdollahi, A., Hahnfeldt, P., Maercker, C., Grone, H., Debus, J., Ansorge, W., Folkman, J., Hlatky, L., Huber, P.E., 2004. Endostatin`s antiangiogenic signaling network. Mol. Cell. 13, 649-663.

Akimoto, S., Tomo, T., Naitoh, Y., Otomo, A., Murakami, A., Mimuro, M., 2007. Identification of a new excited state responsible for the in vivo unique absorption band of siphonaxanthin in the green alga Codium fragile. J. Phys. Chem. 111, 9179-9181.

Carmeliet, P., 2000. Mechanisms of angiogenesis and arteriogenesis. Nature Med. 6, 389-395.

Carmeliet, P., 2005. Angiogenesis in life, disease and medicine. Nature. 438, 932-936.

Carmeliet, P., Jain, R.K., 2000. Angiogenesis in cancer and other diseases. Nature. 407, 249-257.

Chen, G., Niu, X., Chen, X., Li, L., Kuang, T., Li, S., 2008. Characterization of chlorophyll-protein complexes isolated from a siphonous green alga, Bryopsis corticulans. Photosynth. Res. 96, 75-81.

Ferrara, N., 1999. Vascular endothelial growth factor: molecular and biological aspects.

Curr. Top. Microbiol. Immunol. 237, 1-30. 
Ferrara, N., Kerbel, R., 2005. Angiogenesis as a therapeutic target. Nature. 438, 967-974.

Fleurence, J., 1999. Seaweed proteins: biochemical, nutritional aspects and potential uses.

Trends Food Sci. Technol. 10, 25-28.

Folkman, J., 1976. Influence of geometry on growth of normal and malignant cells. Adv.

Pathobiol. 4, 12-28.

Folkman, J., 1995. Angiogenesis in cancer, vascular, rheumatoid and other diseases.

Nature Med. 1, 27-31.

Folkman, J., 2007. Angiogenesis: an organizing principle for drug discovery? Nature Rev.

$6,273-286$.

Folkman, J., Shing, Y., 1992. Angiogenesis. J. Biol. Chem. 267, 10931-10934.

Hanrahan, E.O., Heymach, J.V., 2007. Vascular endothelial growth factor receptor tyrosine kinase inhibitors vandetanib (ZD6474) and AZD2171in lung cancer. Clin. Cancer Res. 134, 4617S-4622S.

Kawasaki, S., Mori, M., Awai, M., 1989. Capillary growth of rat aortic segments cultured in collagen gel without serum. Acta Pathol. Jpn. 39, 712-718.

Kim, K.S., Hong, Y.K., Joe, Y.A., Lee, Y., Shin, J.Y., Park, H.E., Lee, I.H., Lee, S.Y., Kang, D.K., Chang, S.I,, Chung, S.I., 2003. Anti-angiogenic activity of the recombinant kringle domain of urokinase and its specific entry into endothelial cells. 
J. Biol. Chem. 278, 11449-11456.

Kotake-Nara, E., Kushiro, M., Zhang, H., Sugawara, T., Miyashita, K., Nagao, A., 2001.

Carotenoids affect proliferation of human prostate cancer cells. J. Nutr. 131, 3303-3306.

Kotake-Nara, E., Sugawara, T., Nagao, A., 2005. Antiproliferative effect of neoxanthin and fucoxanthin on cultured cells. Fish. Sci. 71, 459-461.

Kruger, E.A., Duray, P.H., Tsokos, M.G., Venzon, D.J., Libutti, S.K., Dixon, S.C., Rudek, M.A., Pluda, J., Allerga, C., Fig, W.D., 2000. Endostatin inhibits microvessel formation in the ex vivo rat aortic ring angiogenesis assay. Biochem. Biophys. Res. Commun. 268, 183-191.

Lindhal, P., Johansson, B.E., Leveen, P., Betsholtz, C., 1997. Pericyte loss and microaneurysm formation in PDGF-B deficient mice. Science. 277, 242-245.

Liu, D., Schwimer, J., Liu, Z., Woltering, E.A., Greenway, F.L., 2008. Anti-angiogenic effect of curcumin in pure versus in extract forms. Pharmaceutical Biol. 46, 677-682.

Mabeau, S., Fleurence, J., 1993. Seaweed in food products: biochemical and nutritional aspects. Trends Food Sci. Technol. 4, 103-107.

Mantell, D.J., Owens, P.E., Bundred, N.J., Mawer, E.B., Canfield, A.E., 2000. 1a,25-dihydroxyvitamin D3 inhibits angiogenesis in in vitro and in vivo. Circ. Res. 
87, 214-220.

Masso-Welch, P.A., Zangani, D., Ip, C., Vaughan, M.M., Shoemaker, S.F., McGee, S.O., Ip, M.M., 2004. Isomers of conjugated linoleic acid differ in their effects on angiogenesis and survival of mouse mammary adipose vasculature 1. J. Nutr. 134, 299-307.

Matsubara, K., Xue, C., Zhao, X., Mori, M., Sugawara, T., Hirata, T., 2005a. Effects of middle molecular weight fucoidans on in vitro and ex vivo angiogenesis of endothelial cells. Int. J. Mol. Med. 15, 695-699.

Matsubara, K., Kaneyuki, T., Miyake, T., Mori, M., 2005b. Antiangiogenic activity of nasunin, an antioxidant anthocyanin, in eggplant peels. J. Agric. Food. Chem. 53, $6272-6275$.

Matsubara, K., Kayashima, T., Mori, M., Yoshida, H., Mizushina, Y., 2008. Inhibitory effects of vitamin $\mathrm{K}_{3}$ on DNA polymerase and angiogenesis. Int. J. Mol. Med. 22, 381-387.

Miyashita, K., Hosokawa, M., 2008. In: Barrow, C., Shahidi, F., editors. Marine Nutraceuticals and Functional Foods. Beneficial health effects of seaweed carotenoid, fucoxanthin. Boca Raton, USA: CRC Press, pp. 297-320.

Miyazawa, T., Shibata, A., Nakagawa, K., Tsuzuki, T., 2008. Anti-angiogenic function of 
tocotrienol. Asia Pac. J. Clin. Nutr. 17, 253-256.

Mizushina, Y., Nakagawa, K., Shibata, A., Awata, Y., Kuriyama, I., Shimazaki, N.,

Koiwai, O., Uchiyama, Y., Sakaguchi, K., Miyazawa, T., Yoshida, H., 2006.

Inhibitory effect of tocotrienol on eukaryotic DNA polymerase $\lambda$ and angiogenesis.

Biochem. Biophys. Res. Commun. 339, 949-955.

Mori, M., Sadahira, Y., Kawasaki, S., Hayashi, T., Notohara, K., Awai, M., 1988.

Capillary growth from reversed rat aortic segments cultured in collagen gel. Acta

Pathol. Jpn. 38, 1503-1512.

Mori, S., Wu, C., Yamaji, S., Saegusa, J., Shi, B., Ma, Z., Kuwabara, Y., Lam, K.S., Isseroff, R.R., Takada, Y.K., Takada, Y., 2008. Direct binding of integrin $\alpha v \beta 3$ plays a role in FGF1 signaling. J. Biol. Chem. 283, 18066-18075.

Romanic, A.M., Burns-Kurtis, C.L., Gout, B., Berrebi-Bertrand, I., Ohlstein, E.H., 2001. Matrix metalloproteinase expression in cardiac myocytes following myocardial infarction in the rabbit. Life Sci. 68, 799-814.

Satchi-Fainaro, R., Mamluk, R., Wang, L., Short, S.M., Nagy, J.A., Feng, D., Dvorak, A.M., Dvorak, H.F., Puder, M., Mukhopadhyay, D., Folkman, J., 2005. Inhibition of vessel permeability by TNP-470 and its polymer conjugate, caplostatin. Cancer Cell. 7, 251-261. 
Scot, E.N., Meinhardt, G., Jaques, C., Laurent, D., Thomas, A.L., 2007. Vtalanib: the clinical development of a tyrosine kinase inhibitor of angiogenesis in solid tumors. Expert. Opin. Invest. Drugs. 16, 367-379.

Shibata, A., Nakagawa, K., Sookwong, P., Tsuzuki, T., Oikawa, S., Miyazawa, T., 2008. Tumor anti-angiogenic effect and mechanism of action of $\delta$-tocotrienol. Biochem. Pharmacol. 76, 330-339.

Shibuya, M., Claesson-Welsh, L., 2006. Signal transduction by VEGF receptors in regulation of angiogenesis and lymphangiogenesis. Exp. Cell. Res. 312, 549-560.

Sugawara, T., Baskaran, V., Tsuzuki, W., Nagao, A., 2002. Brown algae fucoxanthin is hydrolysed to fucoxanthinol during absorption by Caco- 2 human intestinal cells and mice. J. Nutr. 132, 946-951.

Sugawara, T., Matsubara, K., Akagi, R., Mori, M., Hirata, T., 2006. Antiangiogenic activity of brown algae fucoxanthin and its deacetylated product, fucoxanthinol. J. Agric. Food Chem. 54, 9805-9810.

Sugawara, T., Yamashita, K., Asai, A., Nagao, A., Shiraishi, T., Imai, I., Hirata, T., 2009. Esterification of xanthophylls by human intestinal Caco-2 cells. Arch. Biochem. Biophys. 483, 205-212.

Tsuzuki, T., Shibata, A., Kawakami, Y., Nakagawa, K., Miyazawa, T., 2007. Conjugated 
eicosapentaenoic acid inhibits vascular endothelial growth factor-induced angiogenesis by suppressing the migration of human umbilical vein endothelial cells. J. Nutri. 137, 641-646.

Virmani, R., Kolodgie, F.D., Burke, A.P., Finn, A.V., Gold, H.K., Tulenko, T.N., Wrenn, S.P., Narula, J., 2005. Atherosclerotic plaque progression and vulnerability to rupture: angiogenesis as a source of intraplaque hemorrhage. Atheroscler. Thromb. Vasc. Biol. 25, 2054-2061.

Yancopoulos, G.D., Davis, S., Gale, N.W., Rudge, J.S., Wiegand, S.J., Holash, J., 2000. Vascular -specific growth factors and blood vessel formation. Nature. 407, 242-248. Zhu, X., Daghini, E., Chade, A.R., Lavi, R., Napoli, C., Lerman, A., Lerman, L.O., 2008. Disparate effects of simvastatin on angiogenesis during hypoxia and inflammation. Life Sci. 83, 801-809.

Zogakis, T.G., Costouros, N.G., Kruger, E.A., Forbes, S., He, M., Qian, M., Feldman, A.L., Figg, W.D., Alexander, H.R., Liu, E.T., Kohn, E.C., Libutti, S.K., 2002. Microarray gene expression profiling of angiogenesis inhibitors using the rat aortic ring assay. Biotechniques. 33, 664-670. 


\section{Legends to figures}

Fig. 1. Identification and characterization of siphonaxanthin. (a) HPLC chromatogram of crude acetone extract for the detection of siphonaxanthin. UV-vis (b) and mass spectra (C) of siphonaxanthin.

Fig. 2. Effect of siphonaxanthin on HUVEC proliferation. Values are means \pm SD ( $n=3)$. Bars with different superscript are significantly different $(\mathrm{p}<0.05)$.

Fig. 3. Effect of siphonaxanthin on HUVEC chemotaxis. Migrated cells were counted after $6 \mathrm{~h}$ incubation in five microscopic fields at 200X. Values are means of a field \pm SD (n=9). NC, Negative control (medium without VEGF and siphonaxanthin); PC, Positive control (VEGF containing medium without siphonaxanthin). Bars with different superscript are significantly different $(\mathrm{p}<0.05)$.

Fig. 4. Inhibitory effect of siphonaxanthin on HUVEC tube formation on reconstituted basement membrane gel. (a) Microscopic photograph of tube formation on reconstituted gel after $12 \mathrm{~h}$ incubation. (b) Capillary length was measured, and values are means $\pm \mathrm{SD}(\mathrm{n}=3)$. ND, No tube formation detected. Bars with different superscript are significantly different $(\mathrm{p}<0.05)$.

Fig. 5. Inhibitory effect of siphonaxanthin on rat aortic ring ex-vivo angiogenesis. (a) Microscopic photograph of capillary formation. (b) Microvessel length was 
measured on the 7 day culture. Values are means \pm SD $(n=6)$. ND, No vessel formation detected. Bars with different superscript are significantly different $(\mathrm{p}<0.05)$. 
(a)

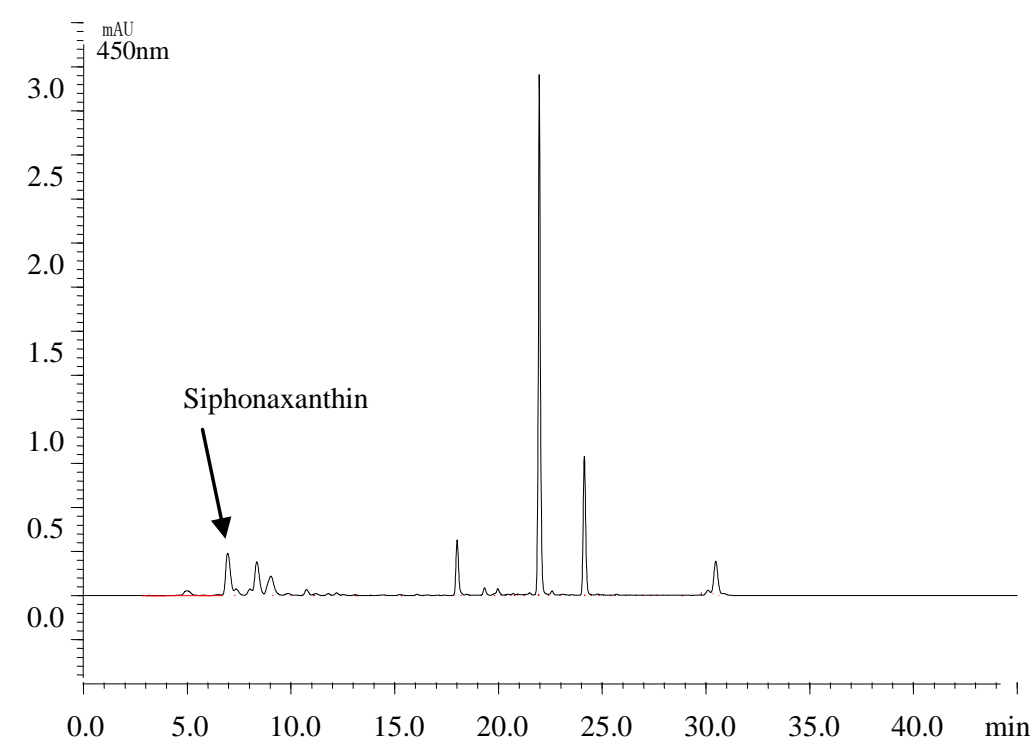

(b)

(c)
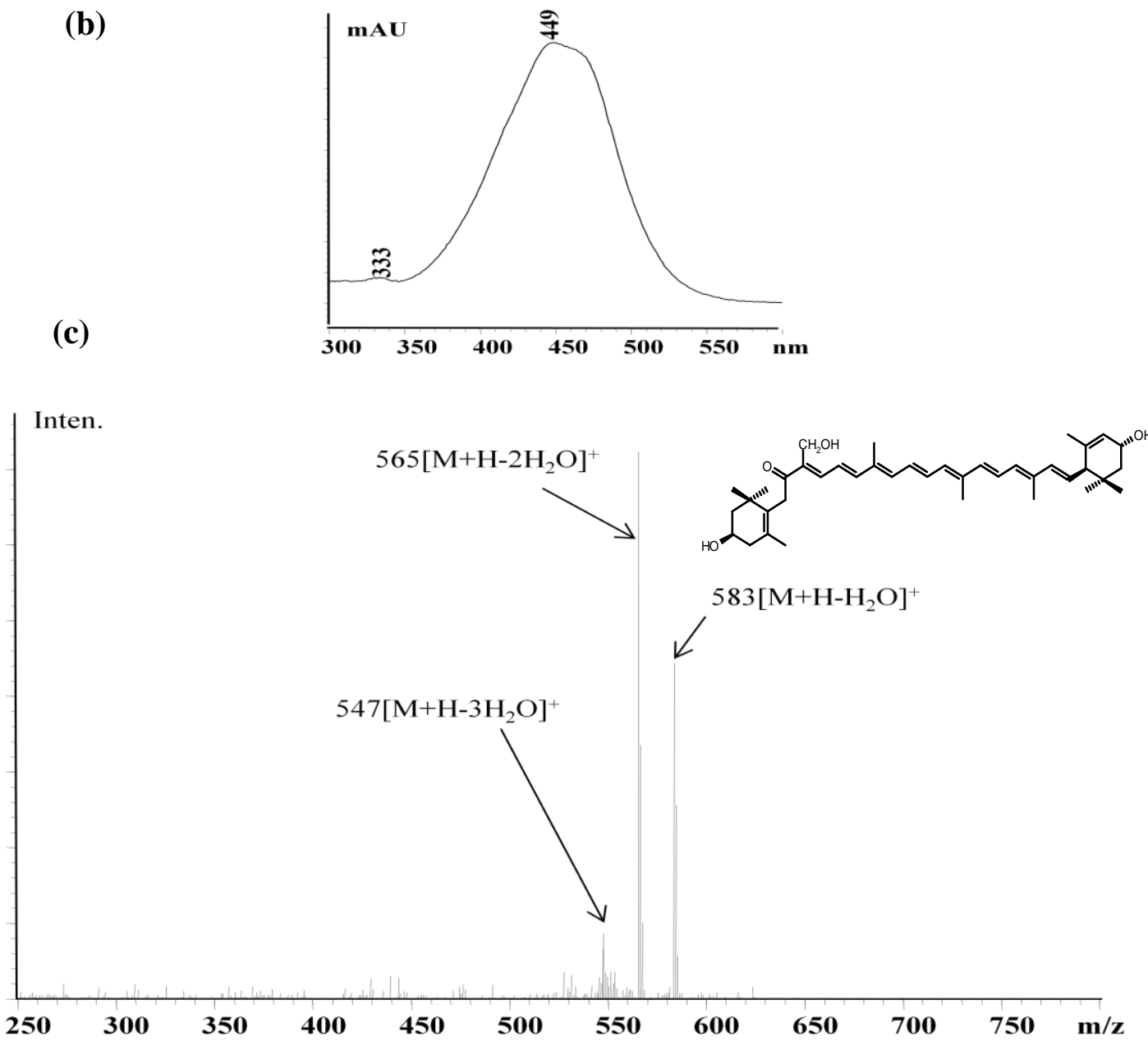

Fig. 1. 


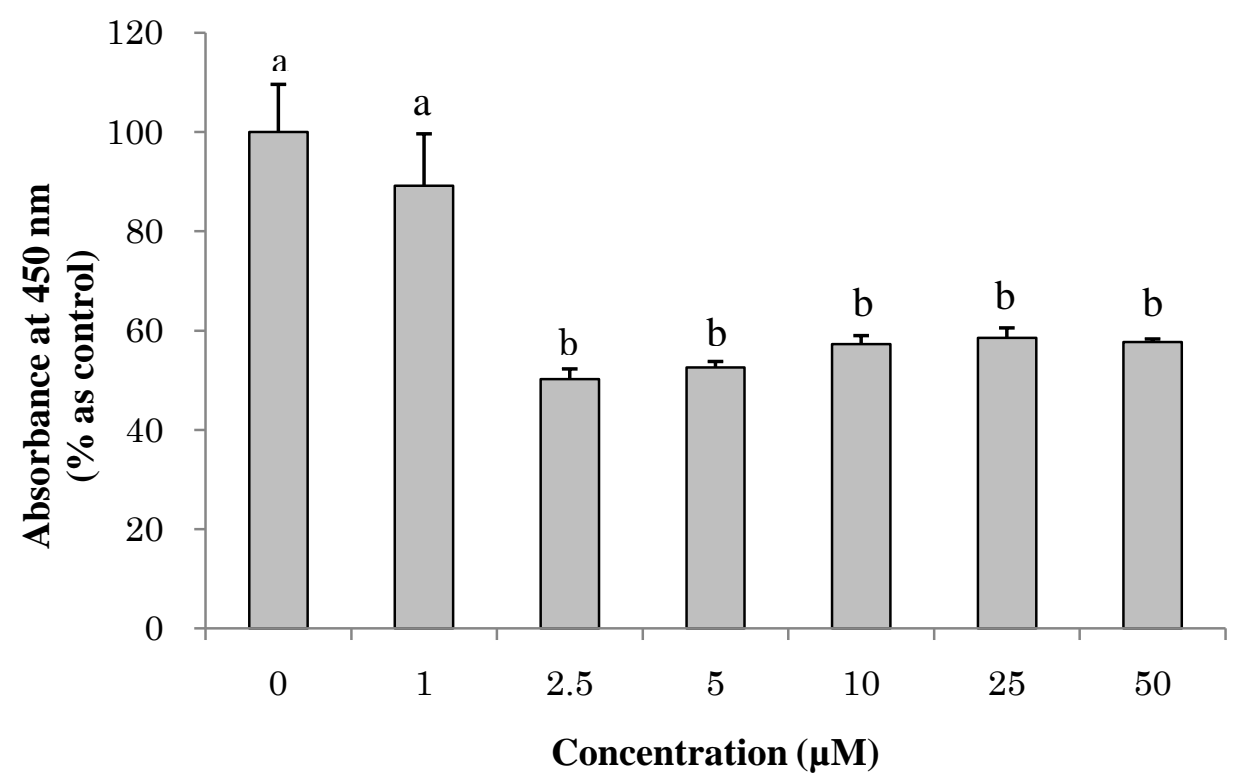

Fig. 2. 


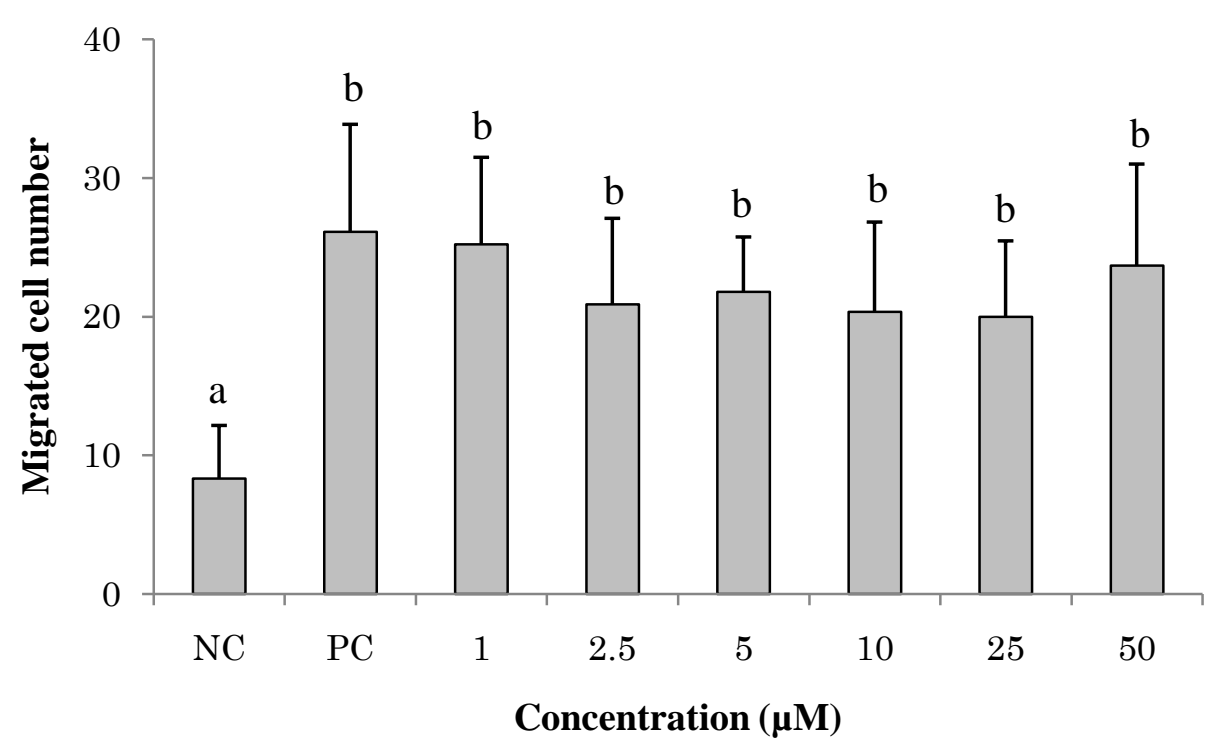

Fig. 3. 
(a)

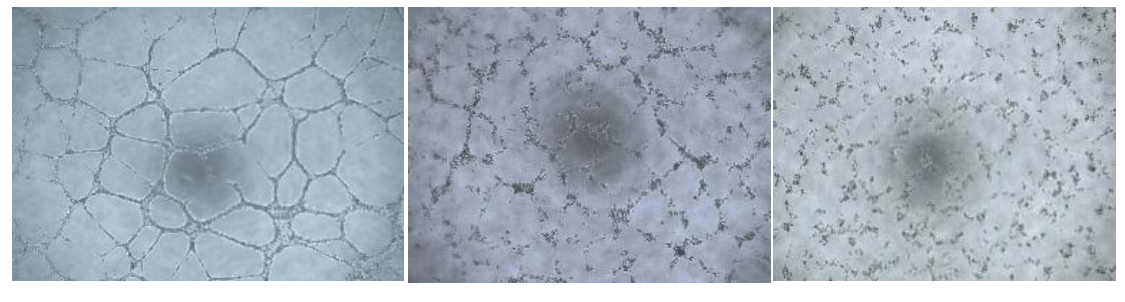

$0 \mu \mathrm{M}$

$10 \mu \mathrm{M}$

$25 \mu \mathrm{M}$

(b)

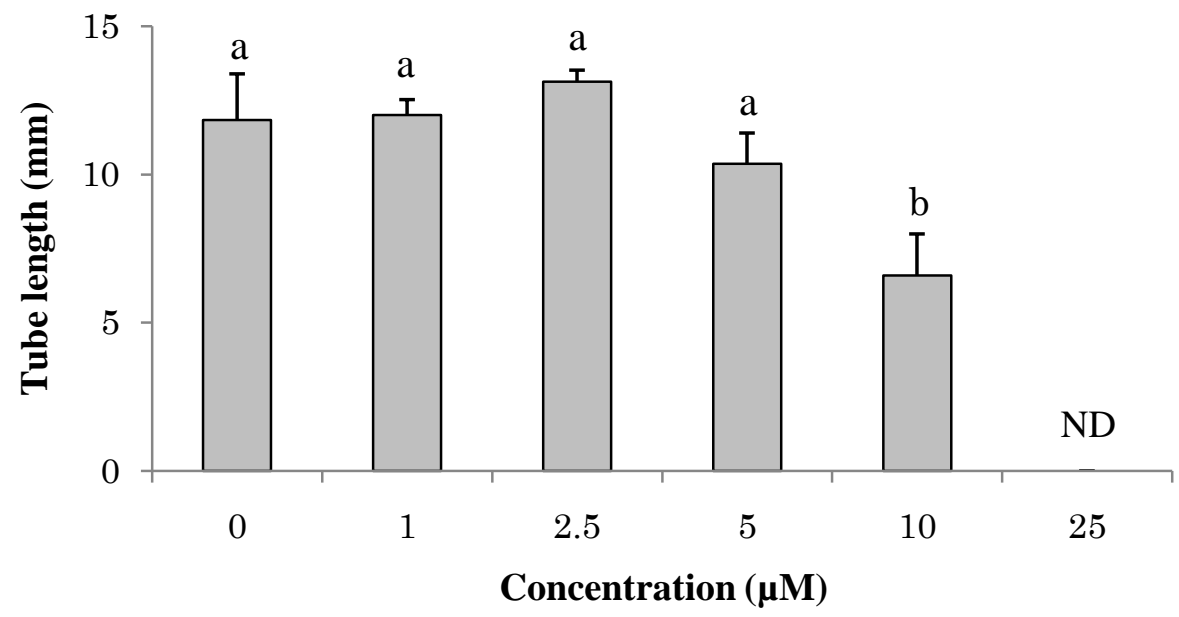

Fig. 4. 
(a)
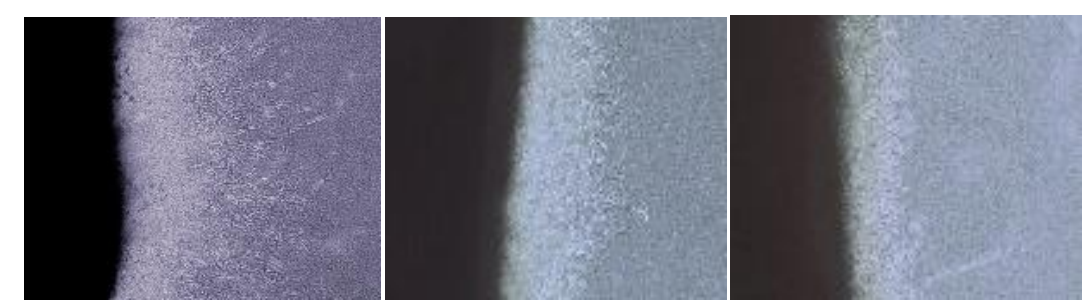

$0 \mu \mathrm{M}$

$5 \mu \mathrm{M}$

$10 \mu \mathrm{M}$

(b)

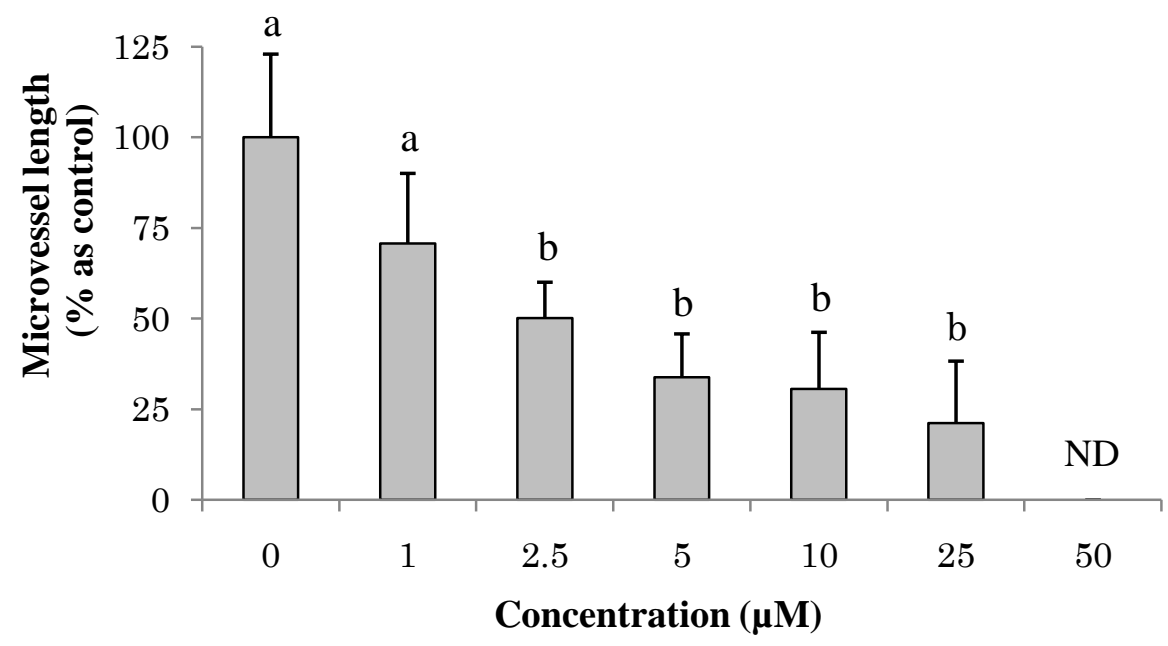

Fig. 5. 